\title{
Sudden Death in Hospital after Discharge from Coronary Care Unit
}

\author{
PETER THOMPSON, GRAEME SLOMAN
}

British Medical fournal, 1971, 4, 136-139

\section{Summary}

In a group of 339 patients with acute myocardial infarction treated in a coronary care unit, 273 left the unit while improving and were expected to leave hospital alive; 23 had a cardiac arrest or died suddenly while still in hospital-17 died immediately or after temporary resuscitation and six were resuscitated to leave hospital alive. Ventricular fibrillation was found in 13 of the 20 patients attended by the cardiac arrest team. The incidents were scattered from the 4th to the 24th day after the onset of infarction. Risk factors in these "late sudden death" patients were compared with the 250 patients who left the unit while improving and did not die or suffer cardiac arrest. The patients susceptible to late sudden death were characterized early in their hospital course by the findings of severe, predominantly anterior infarction, left ventricular failure, persistent sinus tachycardia, and frequent ventricular arrhythmias. It is suggested that such patients be chosen for prolonged observation in a second-stage coronary care unit.

\section{Introduction}

Coronary care units have significantly reduced the hospital mortality of acute myocardial infarction by the aggressive treatment of premonitory arrhythmias in the early stages of the illness (Julian and Oliver, 1968). Sudden death from early ventricular fibrillation is now rare in a coronary care unit (Lown et al., 1969). However, for administrative reasons, the length of each patient's stay in the unit must be limited, varying from 48 hours to a week in most units (Rockwell, 1969), and sudden death continues to be a problem throughout the length of the hospital stay (Robinson, 1965; Restiaux et al., 1967; Pentecost and Mayne, 1968; Spracklen et al., 1968). It is possible that some of these deaths are due to sudden but preventable arrhythmias, and early identification of a high-risk group may permit their selection for extension of coronary care. The present investigation was undertaken to study the circumstances of late sudden death, or cardiac arrest, in these patients and to identify the factors which distinguish them in the early stages of their hospital course.

\section{Patients and Methods}

Between 1 March 1968 and 1 March 1970 a register was kept of every patient admitted to the coronary care unit at the Royal Melbourne Hospital (Sloman and Brown, 1970). Data collected prospectively by the medical and nursing staff of the unit were checked at the time of recording by the unit medical registrar and reviewed at regular intervals by the unit director.

\footnotetext{
Cardiac Department, Royal Melbourne Hospital, Parkville 3050 Victoria, Australia

PETER THOMPSON, M.R.A.C.P., Registrar (Present address: Peter Bent Brigham Hospital, Boston, Mass. 02115, U.S.A.) GRAEME SLOMAN, F.R.C.P.ED., F.R.A.C.P., Directo
}

History and physical examination on admission were elicited by the unit medical registrar or by relieving medical staff. Physical signs were recorded as "present" or "absent;" "gallop rhythm" was recorded if a third or fourth heart sound was heard Chest $x$-ray findings were reported by a radiologist and reviewed by the medical staff of the unit. Arrhythmias noted in the casualty department or during transfer to the unit were recorded by the admitting medical officer; arrhythmias noted during continuous electrocardiographic (E.C.G.) monitoring in the unit were recorded by nursing staff trained in their recognition; illustrative strips for review by the medical staff were taken hourly or when there was any sudden change in cardiac rhythm.

The sources of data and method of collection were similar for all patients; all information was collected prospectively on a specially designed form and later transferred to punch cards. Analysis was performed by an I.B.M. 360 computer using a modified survey-analysis programme (Thompson et al., 1971). Certain clinical (age, site of infarct, blood pressure) and radiological (lung fields, heart size) criteria of severity were selected from the computer printouts for the calculation of a prognostic index by the method of Norris et al. (1969).

If a patient died or had a cardiac arrest while in hospital after discharge from the unit the location and circumstances of death were ascertained by review of the medical and nursing notes and by interview of witnesses when possible. If the cardiac arrest team attended, their report and the electrocardiographic tracings taken at the time of attempted resuscitation were reviewed. The "cardiac arrest rhythm" was taken as the first rhythm observed by the team on its arrival. The timing of the incident was recorded as the number of days after the patients' admission to the unit.

\section{PATIENT GROUPS}

On the basis of the clinical and laboratory findings each patient admitted to the unit was allotted to one of the following diagnostic groups (W.H.O., 1968; Sloman and Brown, 1970): (1) definite acute myocardial infraction, (2) probable acute myocardial infarction, (3) possible acute myocardial infarction, (4) atypical case, (5) no myocardial infarction, another diagnosis made, and (6) insufficient data. There were 339 patients with definite acute myocardial infarction. Fifty-four of them died in the unit.

The clinical course of the 29 patients who died in the hospital after discharge from the unit was reviewed without reference to the information in the computer sheets. Two observers independently adjudged patients either "critically ill, not expected to survive" or "improving, expected to survive" at the time of discharge from the unit. This was, in most cases, an easy judgement; if there was disagreement the patient was classified critically ill, not expected to survive, so that in patients who were improving, expected to survive, death was unexpected on clinical grounds. The 12 patients who were adjudged critically ill, not expected to survive had the following conditions: cardiogenic shock and congestive heart failure (2), cardiogenic shock (3), persistent worsening congestive heart failure (3), stroke (1), post-resuscitation cerebral damage (1), post-infarction ventricular septal defect (1), and prosthetic valve with ball variance and coronary embolus (1).

Of the 273 patients who were improving at the time of discharge from the unit, there were 13 who died suddenly and were 
not resuscitated and four who had a cardiac arrest with temporarily successful resuscitation. In addition, six patients had a cardiac arrest in the wards of the hospital, but were successfully resuscitated and eventually left hospital alive. Thus, there were 23 patients who (1) had definite acute myocardial infarction treated in the unit, (2) were improving when discharged from the unit and were expected to survive, or (3) during their post-unit hospital course had a cardiac arrest or died suddenlythat is, without preceding dyspnoea, prolonged chest pain, or detected arrhythmia. These 23 patients (the "late sudden death" group) form the substance of this report. They are compared with a group of 250 patients (the "post-unit control" group) who were discharged from the unit improving, expected to survive, and whose post-unit hospital course was not complicated by sudden death or cardiac arrest.

\section{Results}

\section{LATE SUDDEN DEATH GROUP}

Age and Sex.-The 21 men and 2 women were aged 31 to 72 , with a mean and S.D. of $56.0 \pm 10.0$ years. There was a predominance of young patients-13 were under 60 and five were under 50 .

Timing of Late Sudden Deaths.-The timing of the post-unit sudden deaths and cardiac arrests is shown in the Chart. There was an even scatter from the 4th day to the 18th day, with one sudden death as late as the 24 th day of stay in hospital.

$$
\Pi=1 \text { sudden death or cardiac arrest }
$$

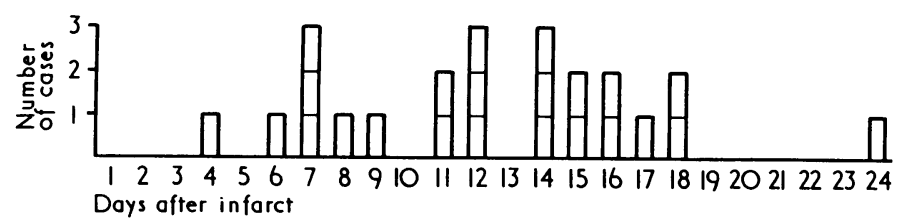

Timing of late sudden death and cardiac arrests in hospital in 23 patients who were improving on discharge from the coronary care unit.

Observations by Cardiac Arrest Team.-The cardiac arrest team attended 20 of these "sudden deaths." Three other patients were found dead in bed, and no resuscitation was attempted. Table I summarizes the arrhythmias recorded by

TABLE I-Correlation of Arrhythmias Recorded Early in Hospital Course with Arrhythmias Recorded by Cardiac Arrest Team at Late Sudden Death or Cardiac Arrest

\begin{tabular}{|c|c|c|c|c|c|}
\hline \multirow{2}{*}{$\begin{array}{l}\text { Arrhythmias in Early } \\
\text { Hospital Course }\end{array}$} & \multicolumn{5}{|c|}{ Arrhythmia at Late Cardiac Arrest } \\
\hline & $\begin{array}{l}\text { Ventricular } \\
\text { Fibrillation }\end{array}$ & Asystole & \begin{tabular}{|c|} 
Complete \\
Heart \\
Block
\end{tabular} & $\begin{array}{c}\text { Sinus } \\
\text { Rhythm }\end{array}$ & Unknown \\
\hline $\begin{array}{ll}\begin{array}{l}\text { Persistent sinus } \\
\text { tachycardia }\end{array} & \ldots \\
\text { Sinus bradycardia } & \ldots \\
\text { Atrial ectopic beats } & \ldots \\
\text { Atrial fibrillation } & \ldots \\
\text { Atrial flutter } & \ldots \\
\text { Atrial tachycardia } & \ldots \\
\text { Ventricular ectopic } & . \\
\text { beats } & \\
\begin{array}{l}\text { Ventricular tachycardia } \\
\text { Primary ventricular }\end{array} \\
\text { fibrillation ... } \\
\text { Total } & \ldots\end{array}$ & $\begin{array}{r}4 \\
1 \\
5 \\
3 \\
2 \\
4 \\
11 \\
8 \\
4 \\
4\end{array}$ & $\begin{array}{l}\text { Z } \\
= \\
= \\
3 \\
1 \\
4\end{array}$ & $\begin{array}{l} \pm \\
= \\
= \\
= \\
-\end{array}$ & $\begin{array}{l}= \\
= \\
= \\
\frac{1}{1}\end{array}$ & $\begin{array}{l}2 \\
1 \\
1 \\
3 \\
- \\
2 \\
2 \\
2 \\
3\end{array}$ \\
\hline
\end{tabular}

the cardiac arrest team and correlates them with the recorded arrhythmias early in the hospital course. Ventricular fibrillation was by far the commonest arrhythmia at late cardiac arrest, and was recorded in 13 of the incidents; in these 13 patients there had been a particularly high incidence of ventricular arrhythmias early in the hospital course: four had been resuscitated from primary ventricular fibrillation, eight had had at least one episode of ventricular tachycardia, and 11 had ventricular ectopic beats recorded.

Outcome.-Of the 13 patients with late ventricular fibrillation 10 were initially resuscitated-six eventually left hospital alive and the other four died three to seven days after resuscitation. Patients with other arrhythmias at cardiac arrest could not be resuscitated, even temporarily.

Findings at Necropsy.-Necropsy examination was performed on 15 of the 17 patients who died. Extensive myocardial infarction was obvious in 13. In two cases there was no macroscopic evidence of recent infarction, but there were old areas of infarction, and recent myocardial necrosis was confirmed histologically. Cardiac rupture through the apex was present in one case. Two cases had a haemorrhagic rim about the area of infarction, suggesting recent extension. There were no cases of recent massive pulmonary embolus. The heart weights in 11 cases ranged from 350 to $685 \mathrm{~g}$.

\section{COMPARISON OF THE TWO GROUPS}

Age.-The post-unit control group was similar in age (mean $55 \cdot 1 \pm 9.9$ years) to the late sudden death group.

Physical Findings on Admission.-Hypotension on admission was not significantly correlated with late sudden death or cardiac arrest, nor was there any significant difference in the means of the systolic blood pressures in the two groups $(130 \pm$ $22.7 \mathrm{~mm} \mathrm{Hg}$ in the late sudden death group and $130 \pm 32.9 \mathrm{~mm}$ $\mathrm{Hg}$ in the post-unit control group (Table II). The observation of sinus tachycardia on admission had no predictive value; this is in contrast to its value when it persisted for the first few days, indicating severe infarction (see below). The presence of basal crepitations was the only physical finding on admission which was significantly more frequent $(P<0.02)$ in the late sudden death group. An enlarged heart and gallop rhythm were also noted more often in the late sudden death group, but the differences were not statistically significant.

TABLE II-Comparison of Frequency of Individual Physical and Chest $X$-ray Findings in Late Sudden Death and Post-unit Control Groups

\begin{tabular}{|c|c|c|c|c|}
\hline & \multirow{2}{*}{$\begin{array}{c}\text { Late Sudden } \\
\text { Death }\end{array}$} & \multirow{2}{*}{$\begin{array}{l}\text { Post-unit } \\
\text { Control }\end{array}$} & \multicolumn{2}{|c|}{ Comparison of Groups } \\
\hline & & & $x^{2}$ & P at 2 D.F \\
\hline 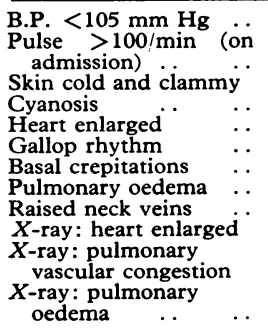 & $\begin{array}{l}12 \%(3) \\
39 \%(9) \\
17 \%(4) \\
17 \%(4) \\
26 \%(6) \\
48 \%(11) \\
83 \%(19) \\
4 \% \%(1) \\
48 \%(11) \\
39 \%(9) \\
70 \%(16) \\
8 \%(2)\end{array}$ & $\begin{array}{l}13 \%(32) \\
33 \%(71) \\
21 \%(53) \\
14 \%(36) \\
14 \%(34) \\
38 \%(96) \\
53 \%(132) \\
7 \% \%(18) \\
42 \%(105) \\
29 \%(72) \\
54 \%(134) \\
7 \%(18)\end{array}$ & $\begin{array}{l}0.4173 \\
0.0264 \\
0.0064 \\
1.7225 \\
0.4395 \\
6.4135 \\
0.0074 \\
1.0272 \\
1.2175 \\
1.5716 \\
0.0239\end{array}$ & $\begin{array}{l}>0.70 \\
>0.50 \\
>0.70 \\
>0.090 \\
>0.05 \\
>0.50 \\
<0.02 * \\
>0.90 \\
>0.20 \\
>0.20 \\
>0.20 \\
>0.70\end{array}$ \\
\hline
\end{tabular}

*Statistically significant

Chest $X$-ray Findings on Admission.-An enlarged heart and pulmonary vascular congestion were more frequent, but not significantly so, in the late sudden death group.

Extent and Location of Infarction on E.C.G.-Of the total unit population with definite infarction $42 \%$ had anterior and $33 \%$ had inferior infarction. However, in the late sudden death group there was a far greater preponderance of anterior infarction $(69 \%)$ than inferior infarction $(13 \%)$, and the incidence of anterior infarction was significantly greater $(P<0.02)$ than in the post-unit control group (Table III). The extent of infarction on the E.C.G. was not compared in the two groups, but on review of the tracings from the late sudden death group 
TABLE III-Comparison of Site of Infarction in Late Sudden Death and Postunit Control Groups

\begin{tabular}{|c|c|c|c|c|}
\hline & \multirow{2}{*}{$\begin{array}{l}\text { Late Sudden } \\
\text { Death }\end{array}$} & \multirow{2}{*}{$\begin{array}{l}\text { Post-unit } \\
\text { Control }\end{array}$} & \multicolumn{2}{|c|}{$\begin{array}{c}\text { Comparison of Groups } \\
\text { by } \chi^{2} \text { Test }\end{array}$} \\
\hline & & & $\chi^{2}$ & $P$ at 2 D.F. \\
\hline 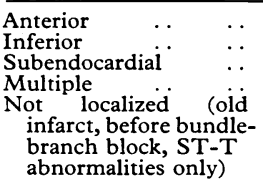 & $\begin{array}{c}69 \%(16) \\
13 \%(3) \\
0 \\
9 \%(2) \\
\\
9 \%(2)\end{array}$ & $\begin{array}{r}39 \%(97) \\
38 \%(94) \\
4 \%(10) \\
6 \%(14) \\
14 \%(35)\end{array}$ & $\begin{array}{l}6 \cdot 1362 \\
4 \cdot 5240 \\
0 \cdot 1578 \\
0.0198\end{array}$ & $\begin{array}{l}<0.02^{*} \\
<0.05^{*} \\
>0.05^{*} \\
>0.70\end{array}$ \\
\hline
\end{tabular}

*Statistically significant.

we were struck by the number with E.C.G. evidence of extensive anterior infarction ( $Q$ waves from $V$ 2-6). There were no patients with subendocardial infarction in the late sudden death group, whereas this was the site of infarction in $4 \%$ of the patients who left hospital alive.

Prognostic Index.-The prognostic index for the late sudden death group was calculated as $6 \cdot 2$, compared with $5 \cdot 6$ for the post-unit control group. These indices compare with 9.2 for the patients who died in the unit.

Arrhythmias Early in Hospital Course.-The patients who died suddenly or had a cardiac arrest late in their hospital course had more arrhythmias early in their hospital course than those who did not. This difference between the two groups was particularly striking when the incidence of ventricular arrhythmias was compared (Table IV). These results refer to ventricular ectopic beats occurring often enough to be recorded electrocardiographically, ventricular tachycardia (a run of three or

TABLE IV-Comparison of Frequency of Ventricular Arrhythmias in Late Sudden Death and Post-unit Control Groups

\begin{tabular}{|c|c|c|c|c|}
\hline & \multirow{2}{*}{$\begin{array}{l}\text { Late Sudden } \\
\text { Death }\end{array}$} & \multirow{2}{*}{$\begin{array}{l}\text { Post-unit } \\
\text { Control }\end{array}$} & \multicolumn{2}{|c|}{$\begin{array}{c}\text { Comparison of Groups } \\
\text { by } \chi^{2} \text { test }\end{array}$} \\
\hline & & & $\chi^{2}$ & $P$ at 2 D.F. \\
\hline $\begin{array}{l}\text { Ventricular ectopic } \\
\text { beats. . ... } \\
\text { Ventricular tachycardia } \\
\text { Primary ventricular } \\
\text { fibrillation ... .. }\end{array}$ & $\begin{array}{l}74 \%(17) \\
48 \%(11) \\
26 \%(6)\end{array}$ & $\begin{array}{l}41 \%(116) \\
14 \%(35)\end{array}$ & $\begin{array}{r}5 \cdot 3270 \\
14 \cdot 8713 \\
\\
12 \cdot 2322\end{array}$ & $\begin{array}{l}<0.05^{*} \\
<0.01^{*} \\
<0.01^{*}\end{array}$ \\
\hline
\end{tabular}

*Statistically significant.

more consecutive ventricular ectopic beats), and primary ventricular fibrillation (ventricular fibrillation in the absence of shock or severe congestive heart failure). Atrial arrhythmias and conduction disturbances in the early hospital course were also more frequent in the late sudden death group, but the differences were individually not significant. Atrial fibrillation occurred in $26 \%$ and $11 \%$ respectively, and complete heart block in $17 \%$ and $8 \%$ respectively. Persistent sinus tachycardia occurred in $48 \%$ of late sudden death patients and in only $25 \%$ of the post-unit control group. This difference was significant $(\mathbf{P}<0.05)$.

\section{Discussion}

Of patients with acute myocardial infarction managed in a coronary care unit, one-third of the hospital deaths occurred after discharge from the unit. Some patients were not expected to survive their hospital course because of persisting heart failure, shock, or other serious illness. However, in most unit survivors early management was regarded as successful, and on clinical judgement they were expected to survive. Of 273 such patients, 23 had a cardiac arrest or died suddenly while still in the hospital-six were resuscitated and 17 died. This mode of death accounted for one-fifth of the hospital mortality.
Analysis of information collected prospectively suggests that many patients showed risk factors for this complication early in their hospital course. The features which were most frequent in patients with subsequent sudden death or cardiac arrest were (1) anterior infarction, (2) severe infarction, and (3) early ventricular arrhythmias.

Though the early mortality in anterior infarction $(17 \%)$ was somewhat greater than in inferior infarction $(12 \%)$, the site of infarction was a more important factor in the subsequent hospital course: late unexpected death or cardiac arrest occurred in $14 \%$ of the patients with anterior infarction and in only $3 \%$ of those with inferior infarction.

Though the deaths were, by definition, "unexpected," most patients, on review, were found to have suffered severe infarctions. However, the deaths which were least expected occurred in those patients whose severe infarction was manifest by subtle signs of severity, such as persistent sinus tachycardia.

The most striking correlations were between the occurrence of late sudden death and ventricular premature beats, ventricular tachycardia, and primary ventricular fibrillation early in the course of infarction. Atrial arrhythmias and conduction disturbances did not correlate as well. In addition to the information from the unit, we have included, where known, any arrhythmias which occurred in the ambulance, emergency ward, or during transfer to the unit. This accounts for the high recorded incidence of early ventricular fibrillation; the latter arrhythmia in particular was associated with sudden death or cardiac arrest in the hospital. Of the 18 patients who had early ventricular fibrillation, survived the unit, and were expected to leave hospital alive, one-third had a cardiac arrest or died suddenly in the hospital wards, most being documented as due to a recurrent episode of ventricular fibrillation. Thus an early episode of primary ventricular fibrillation is of grave significance. This conclusion does not contradict previous studies indicating that resuscitation from ventricular fibrillation has no adverse effect on prognosis once the patient has left hospital (Lawrie, 1969; Stannard and Sloman, 1969); patients in these studies were selected by virtue of having survived their hospital course, excluding many patients with more severe infarction who died in hospital before discharge.

The association of early and late arrhythmias was also noted by Spracklen et al. (1968), who recorded that in their group of 11 patients with late ventricular dysrhythmias, seven had had significant arrhythmias in the unit. A study of patients who left hospital alive after myocardial infarction recorded that arrhythmias in hospital were more closely related to late sudden death than to death after chest pain (Denborough et al., 1968). The frequent observation of ventricular fibrillation by the cardiac arrest team suggests that a ventricular arrhythmia may have precipitated cardiac arrest or sudden death in many of these patients. Whether this was precipitated by a fresh episode of infarction is not clear.

Pentecost and Mayne (1968) found evidence of fresh infarction in three of their seven cases; Spracklen et al. (1968) found postmortem evidence of recent coronary thrombosis in three and electrocardiographic extension of infarction in four of their 11 patients. These authors concluded that late sudden death was preceded by fresh infarction in most cases. In the present series there was evidence of recent extension of infarction in only 2 out of 13 patients who were examined postmortem; both of these had undergone vigorous resuscitative attempts, and the haemorrhagic rim about the infarct may have resulted from this.

In the absence of evidence of fresh coronary thrombi or extension of infarction, we consider it likely that most patients did not suffer reinfarction, and that their sudden death or cardiac arrests were complications of a single severe episode of myocardial infarction. Early arrhythmias are clearly related to the severity of infarction (Stock et al., 1967), and the tendency to late arrhythmias may similarly reflect the extent of tissue necrosis. In addition, persisting high levels of circulating 
catecholamines associated with a severe infarction (Valori et al., 1967; Wallace and Klein, 1968) may have predisposed these patients to serious arrhythmias. A typical "late sudden death" patient reported by Jewitt et al. (1969) had ventricular fibrillation on the 12th day after severe infarction and excessively high urine levels of noradrenaline and adrenaline up to the 11th day.

\section{CHOICE OF PATIENTS FOR MONITORING}

Though the causes of late cardiac arrest and sudden death in hospital remain unclear, these catastrophes occur in nearly $10 \%$ of patients expected to leave hospital alive. The current role of the coronary care unit in monitoring only the first few days after infarction may need re-examination.

It is clearly impossible to continue monitoring for several weeks every patient who is admitted to the unit. Our data indicate that those patients exhibiting the risk factors of anterior infarction, severe infarction, persistent sinus tachycardia, and early ventricular arrhythmias should be carefully sought and then selected for close and prolonged observation. The method of observation depends on the availability of staff and the sophistication of monitoring equipment available. Telemetering devices are not yet far enough advanced for their routine use in every patient; furthermore, treatment of premonitory arrhythmias may be delayed if trained staff are not near the patient. Monitoring of patients in an open ward is ineffective in our experience and in that of others (Hubner et al., 1969; Rawles and Crockett, 1969). The solution must lie in extension of the present coronary care unit concept to allow the higherrisk patient to begin his psychological readjustment and rehabilitation in an area where he is close to the unit staff and is kept under close, but less obtrusive, general and electrocardiographic observation. How long this second-stage coronary care should continue poses an administrative problem. We recorded late sudden death in the third and fourth weeks of hospital stay, and it is possible that some patients will have to be monitored for several weeks. Such second-stage coronary care units should help further reduce the hospital mortality from acute myocardial infarction.

During the preparation of this paper, preliminary successful results from such a unit were reported (Grace and Yarvote, 1971). Information from these units will be relevant to the general problem of identifying which patients with coronary artery disease are susceptible to sudden death. Data accumulation on this question is limited by a relatively low frequency of the catastrophe outside hospital and ignorance of the precipitating arrhythmia thought to be responsible in most cases (Kuller, 1969). By careful monitoring of a group of patients known to be at high risk from sudden death, the relative importance of various risk factors can be evaluated.

We wish to thank Miss Janice Ferguson for secretarial help and Professor R. R. H. Lovell, Professor F. Epstein, and Dr. M. A. Rockwell for valuable comments and criticisms.

This work was supported by grants from U.S. Public Health Service, Heart Disease Central Programme, and the Life Officers Medical Research Fund.

\section{References}

Denborough, M. A., Lovell, R. R. H., Nestel, P. J., and Goble, A. J. 1968). Lancet, 1, 386

Grace, W. J., and Yarvote, P. M. (1971). American fournal of Cardiology, 26, 635 .

Hubner, P. J. B., Goldberg, M. J., and Lawson, C. W. (1969). British Medical fournal, 1,815 .

Jewitt, D. E., et al. (1969). Lancet, 1, 635

Julian, D. G., and Oliver, M. F. (1968). Acute Myocardial Infarction. Edinburgh, Livingstone.

Kuller, L. (1969). American fournal of Cardiology, 24, 617.

Lawrie, D. M. (1969). Lancet, 2, 1085.

Lown, B., Klein, M., and Hershberg, P. I. (1969). American fournal of Medicine, 46, 705 .

Norris, R. M., Brandt, P. W. T., Caughey, D. E., Lee, A. J., and Scott, P. J, (1969). Lancet, 1, 274

Pentecost, B. L., and Mayne, N. M. C. (1968). British Medical fournal, 1, 830.

Rawles, J. M., and Crockett, G. S. (1969)

Restiaux, N. et al (1967). Lancet, $1,1285$.

Robinson, J. S. (1965). American Heart fournal, 69, 285

Rockwell, M. A. (1969). Memorandum RM-5944-12C, Rand Corporation, Santa Monica, California.

Sloman, J. G., and Brown, R. (1970). American Heart fournal, 79, 761.

Spracklen, F. H. N., Besterman, E. M. M., Everest, M. S., Litchfield, J. W., and Petrie, M. (1968). British Medical fournal, 4, 364.

Stannard, M., and Sloman, J. G. (1969). American Heart fournal, 77, 573. Stock, E., Goble, A. J., and Sloman, J. G. (1967). British Medical fournal, 2, 719 .

Thompson, P. L., Wain, C., and Sloman, J. G. (1971). Medical fournal of Australia, 1, 687

Valori, G., Thomas, M., and Shillingford, J. P. (1967). American fournal of Cardiology, 20,605.

Wallace, A.G., and Klein, R.F. (1969). American Fournal of Medical Sciences, $258,139$.

World Health Organization (1968). Regional Office for Europe. Working Group on Ischaemic Heart Disease, Report I. Copenhagen, W.H.O.

\title{
Bronchodilator Effect of Oral Salbutamol in Asthmatics Treated with Corticosteroids
}

\author{
SHEENA S. PARKER, Y. F. J. CHOO-KANG, \\ E. JEAN COOPER, \\ S. J. CAMERON, \\ I. W. B. GRANT
}

British Medical fournal, 1971, 4, 139-142

\section{Summary}

In a double-blind trial the effect on ventilatory function of oral salbutamol (in two different doses) and a placebo were studied in 12 patients with chronic asthma receiving regular maintenance treatment with prednisolone. Salbutamol in a dose of $\mathbf{4} \mathbf{~ m g}$ four times daily, given for a

Respiratory Diseases Unit, Northern General Hospital, Edinburgh EH5 2DQ, and Department of Respiratory Diseases, University of Edinburgh

SHEENA S. PARKER, M.B., CH.B., Registrar

Y. F. J. CHOO-KANG, B.SC., M.R.C.P.ED., Registrar

E. JEAN COOPER, M.B., CH.B., Research Assistant

S. J. CAMERON, M.B., M.R.C.P.ED., Senior Registrar
I. W. B. GRANT, M.B., F.R.C.P.ED., Consultant Physician

period of four weeks, produced a sustained and statistically significant increase in peak expiratory flow rate over the pretreatment recordings. This effect was not observed with a lower dose of salbutamol $(2 \mathrm{mg}$ four times daily) or with a placebo. Salbutamol in the higher dose would seem to be an effective and safe oral bronchodilator that can be recommended for the treatment of mild or moderate asthma. The duration of treatment in this study was, however, limited to four weeks, and it is not known whether effective bronchodilatation would be maintained if the drug were given for longer periods.

\section{Introduction}

An effective long-acting oral bronchodilator with a wide margin of safety would have important advantages over aerosol pre- 